\title{
Antimicrobial Properties of the Methanolic Extracts of Zingiber officinale (Ginger) on Escherichia coli and Klebsiella pneumoniae
}

\author{
Tathagat. E. Waghmare*, Hanumanthappa B Nayaka, Rashmi Gadwal and \\ Prithviraj Bhandare \\ Department of Biotechnology, Gulbarga University, Gulbarga. Karnataka, India. \\ E.Mail: tathagat.waghmare@yahoo.com
}

\begin{abstract}
The emerging trends of multidrug resistance among several groups of microorganisms against different classes of antibiotics led different researchers to develop efficient drugs from various plant sources to counter multidrug resistant strains. This study investigated different solvent extracts of Zingiber officinale, to determine their efficacy against multidrug resistant microbes. The antimicrobial properties of various extract of Zingiber officinale (ginger) against Escherichia coli and Klebsiella pneumoniae that are common causes of gastrointestinal tract infection were investigated using the Agar and tube diffusion method. The results obtained revealed that Methanolic extract of ginger gave the widest zone of inhibition against one out of the two test organisms at the concentration of $20 \mathrm{mg} \mathrm{mL}^{-1}$. However, Klebsiella pneumonia was more sensitive to the extract. It was also observed that the solvent of extraction and its varying concentrations affected the sensitivity of the two test organisms to the plant extract showing that ginger has antimicrobial activities on the test organisms due to its inhibitory effect, thus confirming its use in folk medicine.
\end{abstract}

Key words: Antimicrobial property Methanolic extract, Multi drug resistant, Plant extract.

\section{Introduction}

Many efforts have been made to discover new antimicrobial compounds from various kinds of sources such as plants, animals and microorganisms. A large number of plant products have long been utilized as a source of therapeutic agents worldwide [1-3]. The use of medicinal plants to treat ailment associated with pains is well known through history [4]. Such plants can play important role in drug discovery and this study is logical research strategies in the search for new drugs. Recently, herbal medicines have increasingly been used to treat many diseases including several infections. Plants produce certain chemicals which are naturally toxic to bacteria [5] and many plants have been investigated for the development of novel drugs with therapeutic properties [6]. Ginger has a wide range of action on the human body and has been found effective in the treatment of cataract, heart disease, migraines, struck amenorrhea, athletes foot, bursitis, chronic fatigue, cold, flu, coughs, depression, dizziness, fever, erectile difficulties, kidney stones, Reynard's disease and viral infection [7]. Ginger has also been historically used to treat inflammation which several scientific studies support through one arthritics that showed ginger to be no better that a placebo or ibuprofen. Research on rats suggests that ginger may be useful for treating diabetes; in the West, powdered derived ginger root is made into capsules and sold in pharmacies for medical use [8,9]. In Venezuela, ginger is pounded into a paste and applied to the abdomen for difficult menstruation. In Costa Rica, it is used in a decoction to relieve throat inflammation and asthma with the addition of honey, it is a valued remedy for coughs and bronchitis and also serves as a sudorific in fever. Its natural diuretic stimulates the kidney to flush out toxins faster. In Panama, it is used to relieve rheumatism. Many scientists across the globe have reported antimicrobial properties of several medicinal plants but still a very meager portion of this tremendous potential drug-repertoire has been scientifically screened [10]. A number of medicinal plants have been screened for antimicrobial activity in recent years [11] and efforts have been done to identify their active constituents [12]. The plants extracts possessing bioactivity are essentially evaluated for toxicity and the extracts are usually tested for short or long term toxicity in animal models [13],[14]. Nontoxic extracts possessing good bioactive principles may provide potential antimicrobial leads. Thus the emergence of multiple drug resistance of pathogenic organisms has necessitated a search for new antimicrobial substances from other sources including plants [15].

\section{Materials and Method}

Sampling: The test organisms, Escherichia coli and Klebsiella pneumoniae were collected from Department of Biotechnology, Gulbarga University Gulbarga. The pure culture was sub-cultured on nutrient agar then preserved in the refrigerator at $4^{\circ} \mathrm{C}$ until it was required for study.

The plant material Zingiber officinale (ginger) was purchased from Super market Gulbarga and authenticated at the Department of Botany, Gulbarga University, Gulbarga, Karnataka. 
Extraction of plant material (Ginger): The ginger rhizomes were washed with distilled water and allowed to dry (air-day) for 4 days. Extraction was done using the following procedures; crude extraction methods; cold water extraction and Methanolic extraction. About $150 \mathrm{~g}$ of fresh ginger was blended into zinc powder and soaked in $100 \mathrm{~mL}$ of distilled water for $24 \mathrm{~h}$.

The pulp obtained was left in a clean sterile glass container and shaken vigorously to allow proper extraction and it was filtered using sterile muslin cloth to obtain the filtrate and evaporated to dryness using water bath and stored below ambient temperature.

About $200 \mathrm{~g}$ fresh ginger was soaked in $100 \mathrm{~mL}$ of $95 \%$ methanol for $24 \mathrm{~h}$ to obtain the extract which was evaporated to dryness using water bath and stored as in above $200 \mathrm{~g}$ of fresh ginger was blended and the raw juice was extracted after standing in a clean glass container for $24 \mathrm{~h}$, it was extracted using sterile muslin cloth and the extract was evaporated to dryness using water bath stored.

Preparation of McFarland standard: About 0.5 McFarland equivalent turbidity standard was prepared by adding $0.6 \mathrm{~mL}$ of $1 \%$ barium chloride dehydrate solution $\left(\mathrm{B}_{\mathrm{a}} \mathrm{Cl}_{\mathrm{z}} 2 \mathrm{H}_{2} \mathrm{O}\right)$ to $99.4 \mathrm{~mL}$ of $1 \%$ sulfuric acid solution $\left(\mathrm{H}_{2} \mathrm{SO}_{4}\right)$. A small volume of the turbid solution was transferred to capped tube of the same type that was used to prepare the test and of control inocula. This was stored in the dark at room temperature.

Preparation of inoculums: Inoculums were prepared by direct colony suspension where a small volume of sterile was poured into a test tube to which general colonies of the test organisms taken directly from the plate was emulsified and the suspension adjusted to match the $0.5 \mathrm{McFarland}$ standard which has similar appearance of an overnight broth culture by adding distilled water (Azu and Onyeagba, 2007; Garc and Bruc, 1993).

Antimicrobial screening test: The sensitivity of the test organisms to the extract of Zingiber officinale (ginger) was carried out using the Agar and test tube diffusion method. Total $0.02 \mathrm{~mL}$ of the suspension was added to an already prepared medium using a dropper and a sterile loop was used to spread by streaking the organisms all over the surface of the medium and allow to dry for $5 \mathrm{~min}$. Cups of $6 \mathrm{~mm}$ in diameter was made in the agar using sterile cork borer.

Different dilutions of the plant extracts: Different dilutions of the plant extracts in the order of 20,10,5 and 2.5 and $1.25 \mathrm{mg} \mathrm{mL}^{-1}$ were prepared, respectively in 5 different test tubes and place in a test tube rack. About $0.3 \mathrm{mg} \mathrm{L}^{-1}$ of erythromycin was also prepared alongside which serves are a positive control and distilled water as a negative control. Each concentration was introduced into each hole on the medium, as well with disc soak with the various concentrations of Zingiber officinale extract on the medium and left to stand on the bench for 1 $\mathrm{h}$ for proper diffusion. It was incubated at $37^{\circ} \mathrm{C}$ for $24 \mathrm{~h}$.

\section{Results And Discussion}

The results of the antimicrobial properties of the extracts on the test organisms are shown in Table 1-3. The result of this research indicates that the extracts of Zingiber officinale have antimicrobial properties when the extracts were tested on Klebsiella pneumoniae and E. coli. The widest zone of inhibition was obtained with Klebsiella pneumoniae while E. coli showed a little zone of inhibition. The difference in the zone of inhibition may be directly related to the susceptibility of each test organism to the ginger extracts.

Table. 1 Sensitivity pattern of $\boldsymbol{E}$. coli and Klebsiella pneumoniae to raw Zingiber officinale extract.

\begin{tabular}{|c|c|c|c|c|}
\hline Concentration mg/ml & \multicolumn{2}{|c|}{ Zone of inhibition diameter(mm) } & $\begin{array}{c}\text { Positive control } \\
\text { (Erythromycine) }\end{array}$ & $\begin{array}{l}\text { Negative control } \\
\text { (Distilled Water) }\end{array}$ \\
\hline & E.Coli & K. pneumoniae & & \\
\hline 20 & 0.0 & 4.0 & 26.0 & 0.0 \\
\hline 10 & 0.0 & 6.0 & 26.0 & 0.0 \\
\hline 5 & 0.0 & 7.0 & 26.0 & 0.0 \\
\hline 2.5 & 0.0 & 1.0 & 26.0 & 0.0 \\
\hline 1.25 & 0.0 & 0.5 & 0.0 & 0.0 \\
\hline
\end{tabular}


Antimicrobial Properties of the Methanolic Extracts of Zingiber officinale (Ginger) on ....

Table. 2 Sensitivity pattern of E.coli and Klebsiella pneumonia to cold water extract Zingiber officinale.

\begin{tabular}{|c|c|c|c|c|}
\hline Concentration mg/ml & \multicolumn{2}{|c|}{ Zone of inhibition diameter(mm) } & $\begin{array}{c}\text { Positive control } \\
\text { (Erythromycin) }\end{array}$ & $\begin{array}{l}\text { Negative control } \\
\text { (Distilled Water) }\end{array}$ \\
\hline & E.Coli & K. pneumoniae & & \\
\hline 20 & 13 & 15 & 25 & 0.0 \\
\hline 10 & 11 & 13 & 25 & 0.0 \\
\hline 5 & 9 & 10 & 25 & 0.0 \\
\hline 2.5 & 6 & 4 & 25 & 0.0 \\
\hline 1.25 & 3 & 3 & 21 & 0.0 \\
\hline
\end{tabular}

Table.3 Sensitivity pattern of E.coli and Klebsiella pneumoniae to Methanolic extract of Z. Officinale.

\begin{tabular}{|l|c|c|c|l|}
\hline Concentration mg/ml & \multicolumn{2}{|l|}{ Zone of inhibition diameter(mm) } & $\begin{array}{l}\text { Positive control } \\
\text { Erythromycin) }\end{array}$ & $\begin{array}{l}\text { Negative control } \\
\text { (Distilled Water) }\end{array}$ \\
\hline & E.Coli & K. pneumoniae & & \\
\hline 20 & 14 & 16 & 27 & 0.0 \\
\hline 10 & 12 & 12 & 25 & 0.0 \\
\hline 5 & 8 & 10 & 25 & 0.0 \\
\hline 2.5 & 0 & 6 & 00 & 0.0 \\
\hline 1.25 & 0 & 4 & 00 & 0.0 \\
\hline
\end{tabular}

The factors responsible for this high susceptibitity of Klebsiella pneumoniae to the extract may be attributed to the presence of secondary plant metabolites. Also, the positive control in each of the test organism was sensitive given a value of $26 \mathrm{~mm}$ for E. coli and $26 \mathrm{~mm}$ for K. pneumoniae in the raw extract of ginger, 25 $\mathrm{mm}$ for E. coli and $21 \mathrm{~mm}$ for K. pneumoniae in the Methanolic extract of ginger and $25 \mathrm{~mm}$ for E. coli and 27 $\mathrm{mm}$ for $K$. pneumoniae in the cold water extract of ginger. About $0.5 \mathrm{McFarland}$ given an equivalent approximate density of bacteria $1 \times 10^{-8} \mathrm{cfu} 28$ (Azu and Onyeagba, 2007).

\section{Conclusion}

It became clear in this research that the solvent of extraction affected the degree of antimicrobial activity of the extracts. It was observed that the Methanolic extract of Zingiber officinale gave the widest zone of inhibition in which K. pneumoniae gave a zone of inhibition $(16 \mathrm{~mm})$ using the concentration of $20 \mathrm{mg} \mathrm{mL}^{-}$ ${ }^{1}$ each. This credit of methanolic extraction is due to the fact that methanol is an organic solvent that will dissolve organic compound better (like dissolves like), hence librates the active component required for antimicrobial activity. It was observed that raw extract had activity only on $K$. pneumoniae and no effect was observed on $E$, Coli. The non inhibition of growth in $E$. coli may be due to non liberation of the active constituents of the raw extract. The cold water extract inhibited the growth in both organism at all concentration. This is due to water ability to liberate the active constituent of the plant. It is not worthy that the antibacterial activities of these plant is depended on the concentration of the extract.

\section{References}

[1]. Khan R, Islam B, Akram M, Shakil S, Ahmed A, Ali SM, Siddidui M, Khan AU (2009) Antimicrobial activity of five herbal extracts against multi drug resistant (MDR) strains of bacteria and fungus of clinical origin. Molecules 14: 586-97.

[2]. Gibbons S (2005) Plants as a source of bacterial resistance modulators and anti-infective agents. Phytochem Rev 4: 63-78.

Gottlieb OR, Borin MR, Brito NR (2002) Integration of ethnobotany and phytochemistry: dream or reality? Phytochemistry 60: $145-52$.

[3]. Ernst, E. and M.H. Pittler, 200. Efficacy of ginger for nausea and vomiting : A systematic review of randomized clinical trials. Br. J. Anesthes., 84:367-371.

[4]. Singh B and Bhat TK (2003) Potential therapeutic applications of some antinutritional plant secondary metabolites. J Agric Food Chem 51: 5579-97.

[5]. Tomoko N, Takashi A, Hiromu T, Yuka I, Hiroko M, Munekazu I, Tsutomu N, Kazuhito W (2002) Antibacterial activity of extracts preparated from tropical and subtropical plants on methicillin-resistant Staphylococcus aureus. J Health Sci 48: 273-76.

[6]. Peggy, T.F., 2006. Ginger selection and storage information marco polo Revived interest on Ginger pp: 1.

[7]. Ody, P., 1997. The complete medicinal herbs, dorling Kindersley Ltd. London.

[8]. Ohae, A.,1999. Personal communication taxonomist. National Institute of pharmaceutical research and development (NIPRD) a buja.

[9]. Menghani E, Pareek A, Negi RS, Ojha CK. Search for antimicrobial potential from certain Indian medicinal plants. Res J Med Plants. 2011;5:295-301.

[10]. Premanath R, Sudisha J, Lakshmi Devi N, Aradhya SM. Antibacterial and antioxidant activities of Fenugreek (Trigonella foenum graecum L.) leaves. Res J Med Plants.2011;5:695-705.

[11]. Tijjani MB, Bello IA, Aliyu AB, Olurishe T, Maidawa SM, Habila JD, et al. et al. Phytochemical and antibacterial studies of root extract of Cochlospermum tinctoriumA.rich. (Cochlospermacease) Res J Med Plants. 2009;3:16-22.

[12]. Chavda R, Vadalia KR, Gokani R. Hepatoprotective and antioxidant activity of root bark of Calotropis

[13]. procera R.Br (Asclepediaceae) Int J Pharmacol. 2010;61:937-943.

[14]. Diallo A, Eklu-Gadegbeku K, Agbonon A, Aklikokou K, Creppy EE, Gbeassor M. Acute and sub-chronic (28- Day) oral tocicity studies of hydroalcoholic extract of Lannea kerstingii Engl. and K. krause (Anacardiaceae) stem bark. J Pharmacol Toxicol. 
[15]. Lin RD, Chin YP, Lee MH (2005) Antimicrobial activity of antibiotics in combination with natural flavonoids against clinical extended-spectrum beta-lactamase (ESBL)-producing Klebsiella pneumoniae. Phytother Res 19: 612-17.

[16]. Azu, N.C. and R.A. Onyeagba, 2007. Antimicrobial of extract of allium cepa (onion) and Zingiber, Bacillum subtitis. Int. J. Trop. Med., 3:1-4.

[17]. Garc, L.S. and D.A. Bruc, 1993. Diagnostic medical phraseology. $2^{\text {nd }}$ Edn. American society of Microbiology., Washington DC. 